\title{
A model approach to analyse sowing strategies for maize in southern Mozambique
}

\section{J. M. SCHOUWENAARS \& G. H. PELGRUM}

Department of Hydrology, Soil Physics and Hydraulics, Wageningen Agricultural University, P.O. Box 9101, NL 6700 HB Wageningen, Netherlands

Received 15 February 1989; accepted 15 September 1989

\begin{abstract}
In southern Mozambique, rainfall is concentrated in the rainy period between October and April. Year by year fluctuations of rainfall are extremely wide and rainfall is very erratic. In the sandy soils of the coastal zone, capacity for water retention is very low. Production and consumption of maize is also affected by losses caused by pests and diseases and post-harvest losses. A simple water balance and crop growth model was applied to simulate production of maize for different sowing strategies. Available maize for consumption per month for an average family farming unit was determined for the period 1957-1985. Model parameters which describe soil water availability were varied to study their impact upon sowing strategies. Also values for potential production were varied. For maximizing yearly consumption the preferred strategy almost fully depended on losses by pests and diseases and post-harvest losses. However, regarding the decision criterion of minimizing the periods with food shortage the preferred sowing strategy greatly depended on water-availability and potential production levels.
\end{abstract}

Keywords: sowing strategies, simulation model, optimization, Mozambique

\section{Introduction}

In southern Mozambique, mean annual rainfall decreases from 800-1000 mm near the coast to $550 \mathrm{~mm}$ in the interior $(50-75 \mathrm{~km}$ from the coast). Rainfall is concentrated in the rainy period between October and April. Year by year fluctuations of rainfall are extremely wide and rainfall is very erratic. Maize is the most important cereal crop. Its average production is very low (less than $1000 \mathrm{~kg} \mathrm{ha}^{-1}$ ) and yields vary considerably with the amount and distribution of rainfall during the growing period. In the sandy soils, capacity for water retention is very low (5-10\%). It seems common practice to sow maize in small quantities throughout the whole year, whenever rainfall is sufficient. However, the most important period for sowing is September-October. This is not the most favourable period from an agrohydrological viewpoint. Risks for water deficiency are lower when sowing in the period December-January. Probably, earlier sowing can be explained by the almost perma- 
Table 1. Monthly precipitation (mm) and evaporation data (mm) for Manhica (period 1957-1985).

\begin{tabular}{lcrrr}
\hline Month & \multicolumn{2}{l}{ Precipitation } & \multicolumn{2}{c}{ Penman evaporation } \\
\cline { 2 - 4 } & L & M & H & \\
Sep & 9 & 24 & 45 & 119 \\
Oct & 38 & 59 & 73 & 150 \\
Nov & 48 & 65 & 101 & 158 \\
Dec & 57 & 78 & 150 & 170 \\
Jan & 73 & 116 & 217 & 167 \\
Feb & 47 & 132 & 234 & 138 \\
Mar & 57 & 100 & 132 & 127 \\
Apr & 41 & 58 & 111 & 100 \\
May & 15 & 31 & 87 & 76 \\
Jun & 10 & 19 & 39 & 59 \\
Jul & 0 & 14 & 34 & 64 \\
Aug & 3 & 16 & 33 & 86 \\
Year & 726 & 932 & 1183 & 1414 \\
\hline
\end{tabular}

Data from Mozambican Meteorological Service

$1 \mathrm{~L}$ in $25 \%$; $\mathrm{M}$ in $50 \%$; $\mathrm{H}$ in $75 \%$ of the years, precipitation is lower; i.e.: for $\mathrm{L} 75 \%$, for $\mathrm{M} 50 \%$ and for $\mathrm{H} 25 \%$ probability of exceeding the indicated value.

2 For net short-wave radiation the following equation was used: $R_{\mathrm{n}}=0.75 R_{\mathrm{sa}}(0.29+0.42 n / N)$ where $R_{\mathrm{sa}}$ is short-wave radiation at top of atmosphere and $n / N$ is sunshine (fraction).

nent food shortage, inducing people to sow as early as possible, and by the higher risks for damage caused by pests and diseases in later periods.

Model approach was used to understand better the logic of certain sowing strategies. Therefore a selection was made of some environmental factors which were expected to play a role in preferences for sowing strategies. Emphasis was laid on water availability, depending on rainfall, soil properties and plant density. The impact of losses caused by pests and diseases and by inadequate storage facilities was analysed in quantitative terms. The effect of different potential production levels under the poor soil fertility conditions was studied. The objective of this study was to analyse the relative importance of the selected factors to improve our understanding of a part of the complex problems related to decisions on sowing strategies. Therefore, a sensitivity analysis was made. The period 1957-1985 was examined. In the study area was Manhica, situated at about $20 \mathrm{~km}$ from the coast $\left(25^{\circ} 24^{\prime} \mathrm{S}\right.$, $\left.32^{\circ} 48^{\prime} \mathrm{E}\right)$. Monthly precipitation and evaporation data are listed in Table 1.

\section{Simulation of sowing strategies}

Rainfed crop production in the sandy coastal zone of southern Mozambique is practised mainly by small-family farming units. Each family cultivates different fields (machambas) with a total area of 1-2 ha. Most important food crops are cassava (Manihot sp.), maize (Zea mays), groundnut (Arachis hypogaea), sweet potato (Ipomoea batatas), cowpea (Vigna sp.) and pigeonpea (Cajanus cajan). Commonly 
mixed cropping is practised with low plant densities for maize.

Actual production of maize for an average family unit was calculated, assuming that the area used for maize was 1.2 ha year $^{-1}$. For an average family, required consumption for calories and proteins was set at $130 \mathrm{~kg}$ per month. To satisfy protein needs, a minimum of $100 \mathrm{~kg}$ per month should be consumed. Actual consumption of maize in a certain month was determined taking into account the stored quantities and the perspectives of the standing crops. In reality the availability of alternative food is very important, but in this study attention was only given to maize production and maize consumption. The sowing rate was set at $25 \mathrm{~kg} \mathrm{ha}^{-1}$. With these assumptions it was possible to determine actual available maize for consumption per month over a longer period and to evaluate different sowing strategies. The following strategies were examined:

- Strategy 1: 0.1 ha was sown every month.

- Strategy 2: 0.4 ha was sown in September, December and March, respectively.

- Strategy 3: 1.2 ha was sown in December.

When in a given month rainfall was insufficient, the area that should be sown in that month (according to the strategy) was sown as soon as rainfall permitted, in addition to other areas planned for sowing.

Weight losses of 20-50\% are very common when food is stored for one year (Hall, 1970). To study the impact of these losses the monthly reduction of stored quantities was set at 0,5 and $10 \%$, respectively.

When selecting a preferable strategy the problem arises that the criteria to decide upon are not well understood and vary. For instance, when alternative food is available throughout the whole year, then for maize preference might be given to the maximization of production. However, when this is not available, preference might be given to the minimization of the length of the periods with shortage of maize ('critical periods'). A critical period was defined as a period in which consumption was less than $50 \%$ of the minimal required maize food. An analysis was made for critical periods of 3 months and for periods of more than 3 months.

\section{Modelling yields for maize}

\section{A simple approach: the SWETAM model}

In the water balance model SWETAM, variations in soil water content within the rootzone were simulated using simple concepts of water losses by evaporation from bare soil and through crop canopy. Details of this model were described by Schouwenaars (1988). The ratio between actual and potential transpiration was described as a function of the volumetric water content of the soil. In the sandy soils of the coastal zone the low water holding capacity creates deep redistribution of infiltrated water. For these soils a uniform soil water distribution within the rootzone was assumed and water flow within the soil profile was disregarded.

These assumptions required that the soil profile in the rootzone was rather uniform and capillary fluxes from the groundwater were negligible. In the SWETAM model, run off and the interception of precipitation by the crop was neglected. 
Water balance terms were calculated for 5-day periods (pentads). For a given pentad the amount of available water in the rootzone depended on rooting depth, soil water retention characteristics and the prevailing meteorological conditions (precipitation) in the preceding pentads. Field observations indicated that crops were sown when total precipitation within a 5-day period exceeded $20 \mathrm{~mm}$. Sowing conditions were analysed for each month in the subsequent years. If in a certain month conditions were suitable for sowing the water balance terms during the growing period were determined. This is only done once a month. In reality there might be more periods within a month with favourable conditions for sowing.

Initial soil water storage was determined using precipitation data over the 30 days preceding the sowing date and taking into account the losses by evaporation during this period.

In southern Mozambique in many fields sweet potato and groundnut are grown in between the maize plants. Normally these intercropped plants only cover a small fraction of the soil $(<25 \%)$ and their growing periods do not correspond to those of maize. For the analysis of the water balance they were neglected. In this study, maize with a maximum soil cover of $50 \%$ (low plant density) and of $100 \%$ (high plant density) were considered. Rooting depth was determined as a linear function of the square root of time.

Crop coefficients for maize as given by Doorenbos \& Pruitt (1977) were used to determine potential evapotranspiration $\left(E T_{\text {pot }}\right)$ from Penman-evaporation data. The ratio between potential transpiration $\left(T_{\text {pot }}\right)$ and $E T_{\text {pot }}$ was taken as a linear function of the soil cover. The latter was simply described as a function of time (assuming an S-shaped growing curve). Maximum soil cover was variable.

\section{Yield reduction by water deficit}

Little research has been performed on the impact of water deficit on yields of the local varieties of maize in southern Mozambique. Doorenbos \& Kassam (1979) proposed the following simple relation:

$$
1-Y_{\text {actual }} / Y_{\text {potential }}=\mathrm{f}\left(1-T_{\text {actual }} / T_{\text {potential }}\right)
$$

in which $Y$ is yield $\left(\mathrm{kg} \mathrm{ha}^{-1}\right)$ and $T$ transpiration $(\mathrm{mm})$. The ratio $Y_{\mathrm{act}} / Y_{\mathrm{pot}}$ is known as relative yield. The ratio $T_{\text {act }} / T_{\text {pot }}$ is known as relative transpiration. The reduction factor $f$ was set at 0.4 for the vegetative period (0-50 days), 1.5 for the flowering period (51-65 days), 0.5 for the seed formation period (66-105 days) and 0.2 for the ripening period (106-115 days) (Doorenbos \& Kassam, 1979). For Manhica, relative yields were calculated (Table 2 ).

Schouwenaars et al. (1988) evaluated both simple and detailed water balance models (SWETAM versus SWATRE') and crop growth models (Doorenbosapproach versus WOFOST ${ }^{2}$ ). They selected periods with big differences in distri-

\footnotetext{
1 For a description of SWATRE see Belmans et al., 1983.

2 Developed at the Centre of World Food Studies, Wageningen; see van Keulen \& Wolf, 1986.
} 
Table 2. Simulated relative yields ${ }^{1}$ for maize at Manhica.

\begin{tabular}{|c|c|c|c|c|c|c|c|c|c|c|c|c|}
\hline \multirow[t]{2}{*}{ Year $^{2}$} & \multicolumn{12}{|c|}{ Month of sowing } \\
\hline & Sep & Oct & Nov & Dec & Jan & Feb & Mar & Apr & May & Jun & Jul & Aug \\
\hline $56-57$ & - & - & - & - & - & - & - & - & 5 & 4 & 3 & 1 \\
\hline $57-58$ & & 4 & & 6 & 5 & 5 & 4 & 3 & & & & \\
\hline $58-59$ & 6 & 6 & 6 & 4 & 4 & 5 & 5 & & 4 & & 3 & \\
\hline $59-60$ & 4 & 3 & 4 & 5 & 5 & 4 & 6 & 3 & 3 & & & \\
\hline $60-61$ & 5 & & 4 & 3 & 2 & 3 & 2 & & & 5 & 3 & 3 \\
\hline $61-62$ & & 4 & 5 & 3 & 1 & & 1 & & & & & \\
\hline $62-63$ & & 5 & 4 & 4 & 4 & 4 & 6 & 4 & 5 & 2 & 1 & \\
\hline $63-64$ & & & 6 & 5 & 5 & 3 & 3 & 3 & & & & \\
\hline $64-65$ & & 5 & 3 & 3 & 5 & 5 & 4 & & 2 & & 3 & 5 \\
\hline $65-66$ & 5 & 3 & 4 & 6 & 6 & 5 & 5 & & 4 & 2 & & \\
\hline $66-67$ & 3 & 1 & 4 & & 6 & 6 & 4 & 4 & & & 1 & \\
\hline $67-68$ & & 1 & 4 & & 5 & 5 & & 4 & & & & \\
\hline 68-69 & 4 & & 2 & & 6 & 6 & 5 & 3 & 2 & & & \\
\hline $69-70$ & & 4 & 2 & 1 & & & & & 4 & 1 & & \\
\hline $70-71$ & 4 & 4 & 4 & 6 & 5 & 5 & 3 & 3 & 3 & & & \\
\hline $71-72$ & & 3 & & 6 & 5 & 5 & 6 & 4 & 3 & & & \\
\hline $72-73$ & & 4 & 3 & 3 & 5 & 6 & 4 & 3 & 3 & & 2 & \\
\hline $73-74$ & 4 & 4 & 4 & 6 & 6 & 6 & 5 & 3 & 1 & & & \\
\hline $74-75$ & & 5 & 5 & 6 & 6 & 4 & 4 & & 4 & 1 & & \\
\hline $75-76$ & & 2 & 3 & 3 & 2 & 6 & 5 & 5 & 4 & 1 & & \\
\hline $76-77$ & & & 4 & 6 & 6 & 3 & 3 & 1 & & & & \\
\hline $77-78$ & & & 5 & 6 & 6 & 4 & 2 & 3 & & & 2 & \\
\hline $78-79$ & 4 & & 2 & 1 & 4 & 4 & 4 & - & - & - & - & \\
\hline $79-80$ & 4 & 3 & 5 & 6 & 5 & 4 & 1 & 2 & - & - & - & - \\
\hline $80-81$ & - & - & 5 & 4 & 2 & 5 & 5 & 2 & 2 & & & \\
\hline $81-82$ & 2 & 5 & 5 & 5 & 2 & 5 & 3 & 3 & & & & \\
\hline $82-83$ & 1 & 1 & & & 2 & & 3 & & 4 & & & 3 \\
\hline $83-84$ & & 5 & 3 & 5 & 4 & 5 & 2 & 5 & & & 3 & \\
\hline $84-85$ & 3 & 1 & 3 & 6 & 6 & 6 & 5 & & & & & \\
\hline
\end{tabular}

1 Defined as the ratio between actual production (with limited water use) and potential production. Classification: blank: no sowing, - : no data, $1: 0.00-0.25,2: 0.25-0.37,3: 0.38-0.50,4: 0.50-0.62,5$ : $0.63-0.75,6: 0.75-1.00$ of potential production.

229 years analysed, period 1957-1985.

bution and total amount of rainfall. Then both water balance models were applied for the same set of data for precipitation, potential evapotranspiration, rooting depth, soil cover and soil characteristics. Differences in the estimation of actual transpiration between both water balance models appeared to depend on the prevailing rainfall characteristics. Only for extremely dry or wet periods systematic differences between the results could be found. When dry periods coincided with droughtsensitive growth stages with the SWETAM model considerable errors in the estimation of relative yields could be made. For all selected periods the relative yields obtained with the SWATRE-Doorenbos combination were very similar to those obtained with the SWATRE-WOFOST model. For the objectives of this study the simple approach of Doorenbos \& Kassam gave satisfactory results. 


\section{Potential yields}

Actual production levels mostly vary between 500 and $1000 \mathrm{~kg} \mathrm{ha}^{-1}$. Little information is available about the potential production levels. Relative yield $\left(\mathrm{kg} \mathrm{ha}^{-1}\right)$ was calculated by multiplying the ratio $Y_{\text {actual }} / Y_{\text {potential }}$ by potential production. Potential production was defined as the yield under optimal water supply and (low) natural fertility, without reduction caused by pests and disease. When fertility is the main limiting factor it is questionable whether differences in $\mathrm{CO}_{2}$-assimilation within a year, lead to differences in potential production levels as defined above. It was decided to use potential production levels which varied as a result of reduced $\mathrm{CO}_{2}$-assimilation in colder periods, following the method described by Goudriaan (1982). Maximum potential production levels (i.c. under maximum $\mathrm{CO}_{2}-$ assimilation) of $1700 \mathrm{~kg} \mathrm{ha}^{-1}$ and $2300 \mathrm{~kg} \mathrm{ha}^{-1}$ were used as input in the SWETAM model.

\section{Yield reduction by pests and diseases}

The best months for growing maize from an agrohydrological viewpoint (i.c. with lowest risks for water deficit) unfortunately coincide with the warmest period (December and January, see Table 1). In this period, pests and diseases cause severe yield reduction (Nunes et al., 1986). To assess the negative impact of pests and diseases, potential production levels were reduced, only for growing periods starting in the period September-February. The value for this reduction factor was uncertain, so different values were used to study its effect on sowing strategies. For growing periods starting in the period October-January, values of 0,25 and $50 \%$ were used. The period of gradual increase and decrease of occurrence of pests and diseases was taken into account by taking only half of these values for growing periods starting in September and February.

\section{A sensitivity analysis}

\section{Water availability}

For modelling water use by a crop it has to be known which part of the total available soil water is easily available. The transpiration rate (i.e. the ratio $T_{\text {act }} / T_{\text {pot }}$ ) is found to be relatively unaffected by the soil water content over a considerable range, and only when the water content falls below a given value, the transpiration rate starts to decrease (Gardner, 1983). In the SWETAM model both the total available water and the fraction which is easily available could be varied. After depletion of the easily available water, the water uptake (i.e. transpiration rate) was supposed to decrease linearly with the water content. Using these concepts in the SWETAM model, 3 different options (A, B and C) were used (Fig. 1a). With Option A, plants are more vulnerable for short dry periods than with Option $\mathrm{C}$, where during the first period of drought plants still are able to extract enough water from the soil to satisfy their needs. For the sensitivity analysis the differences between the above-mentioned 


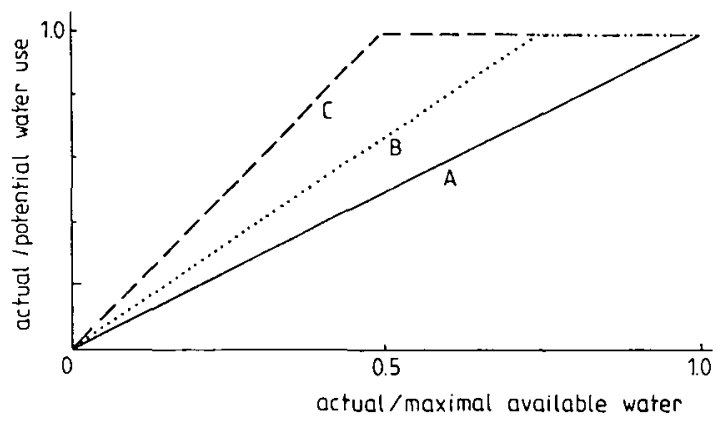

b

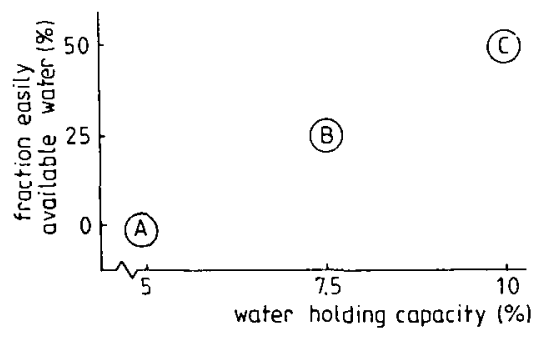

Fig. 1a. The ratio between actual and potential water use (relative water use) as a linear function of the ratio between actual and maximal available water for 3 options ( $A, B$ and $C$ ).

Fig. 1b. The selected combinations of water holding capacity and fraction easily available water (the latter refers to the traject in Fig. 1a where relative water use equals 1). The relative water availability is low for Option A, medium for B and high for C.

Options $\mathrm{A}, \mathrm{B}$ and $\mathrm{C}$ were enlarged by varying the maximum water holding capacity (set at $5 \%, 7.5 \%$ and $10 \%$ for Options A, B and C, respectively). The final combinations are presented in Figure $1 \mathrm{~b}$.

In combination with the different values describing the impact of pests and diseases and storage losses, simulations were carried out. Figure $2 a$ and Figure 3a present results for the criterion of maximizing average yearly consumption. Figure $2 \mathrm{~b}$ and $3 \mathrm{~b}$ present results for the criterion of minimizing the number of critical periods. For every combination of losses 3 values are presented, the best of which is indicated. The upper value is for Strategy 1, the medium one is for Strategy 2 and the lower one is for Strategy 3.

It is possible to analyse alterations in preferences caused by changed values for losses. In the figures lines are distinguished indicating for which values at both axes (losses) there are changes in the optimum strategy. 


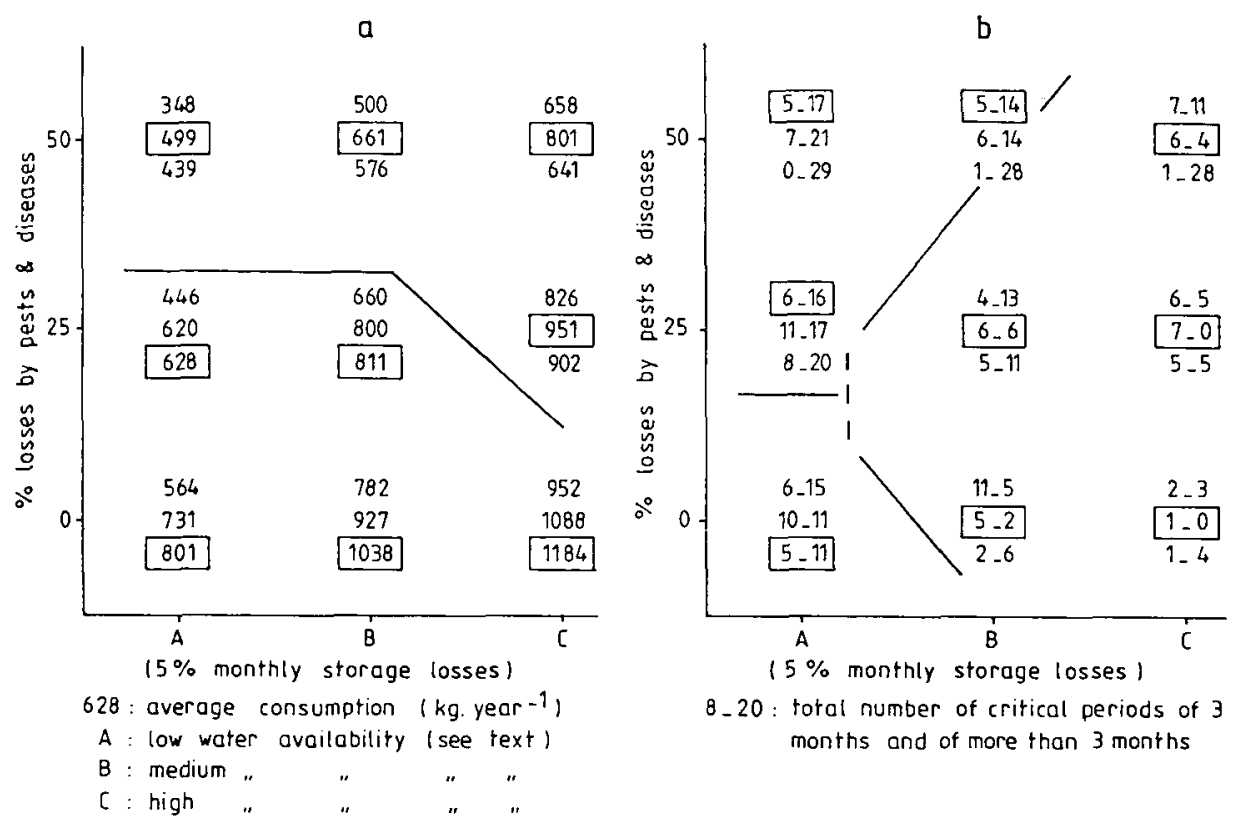

Fig. 2. Optimum strategies for maize as influenced by water availability (A, B and C) and for different losses by pests and diseases. a: for maximizing average yearly consumption; $b$ : for minimizing critical periods.

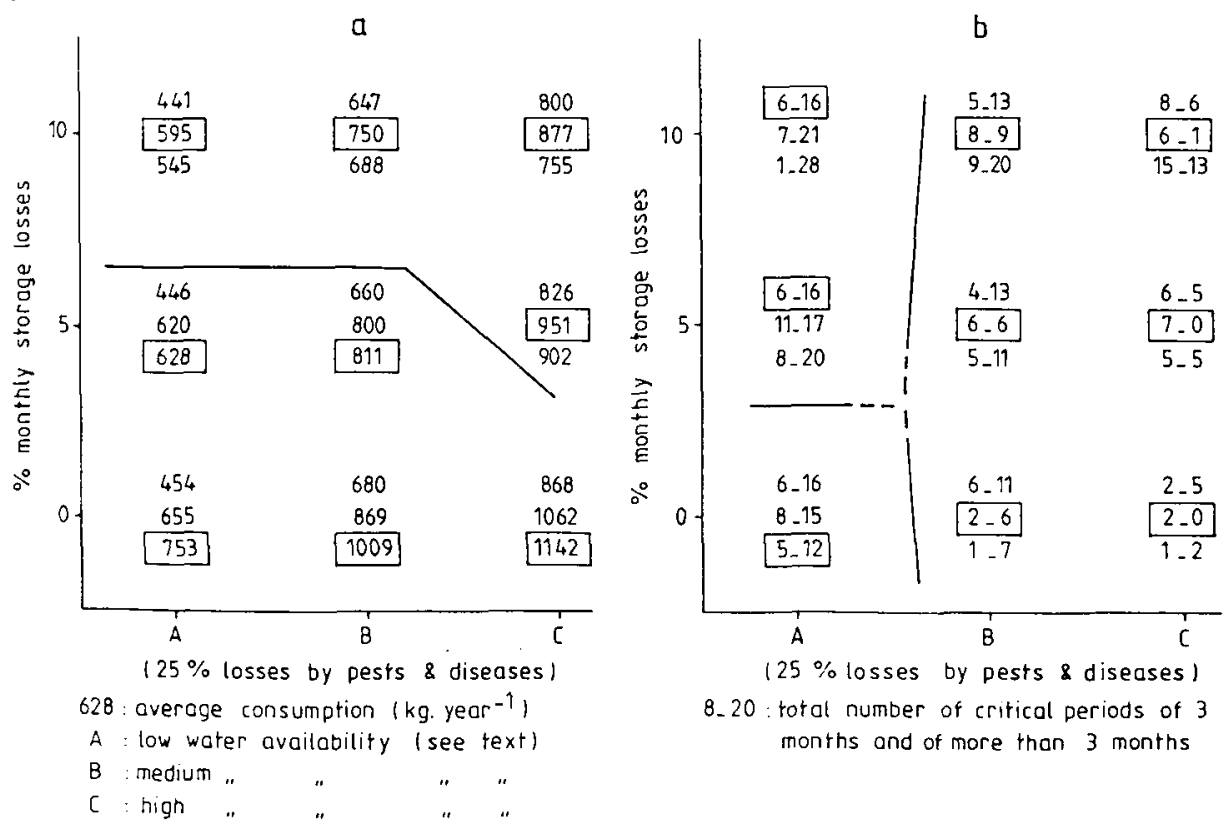

Fig. 3. Optimum strategies for maize as influenced by water availability (A, B and C) and for different storage losses. a: for maximizing average yearly consumption; $b$ : for minimizing critical periods. 

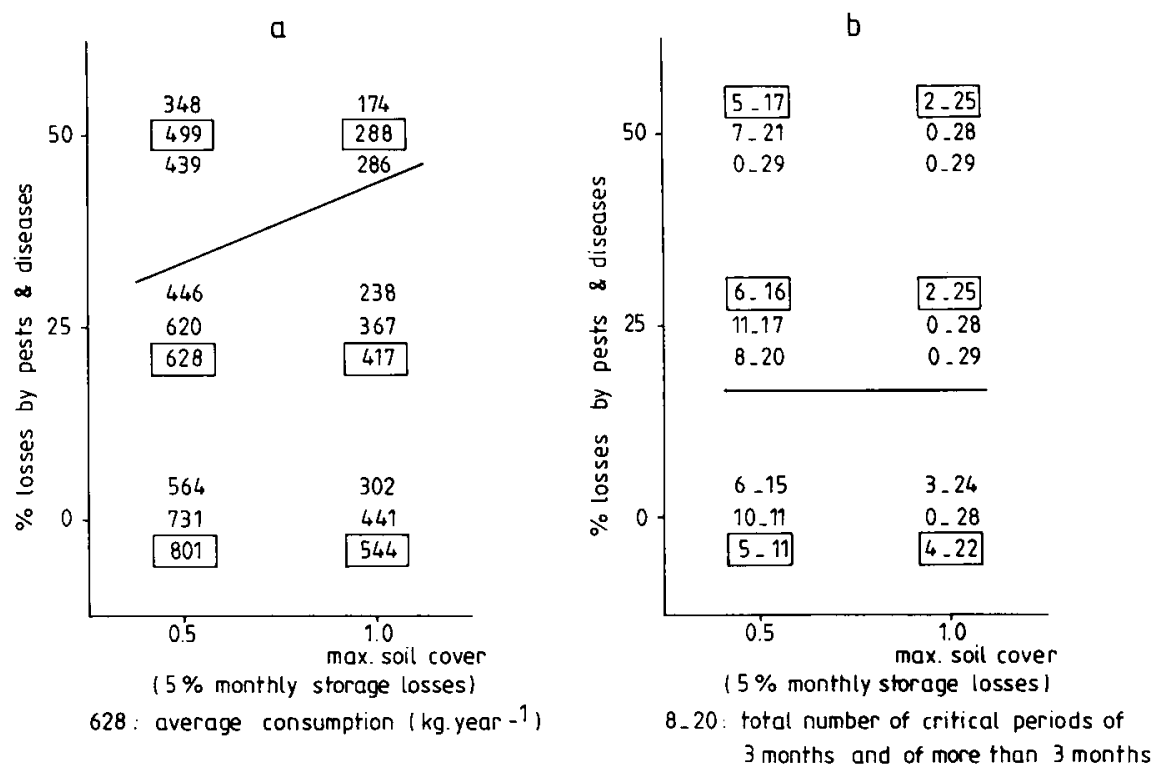

Fig. 4. Optimum strategies for maize as influenced by plant density. a: for maximizing average yearly consumption; $b$ : for minimizing critical periods.

\section{Plant density}

The ratio between potential transpiration and potential soil evaporation is a function of the soil cover development. In dry periods, actual soil evaporation decreases rapidly when the top layer dries out. Hence, with low plant densities more water per unit area is available for transpiration than with high plant densities. Under low densities, a plant which expands its roots horizontally can profit from this extra water. It is not well known under which plant densities there is an optimum use of the available soil water. This also holds for the optimum use of available nutrients. First results of field trials in Maputo indicated that the optimum plant density was different for fertilized and non-fertilized plots.

The impact of plant densities upon actual transpiration was examined with some simplifications. Maximum soil cover at the end of the growing period was set at $50 \%$ and $100 \%$. It was assumed that in the first case the roots of a single maize plant occupy a soil volume twice as large as in the latter case. Another simplification was made by assuming that potential production per ha was equal for the two plant densities. Such a simplification was questionable because it can be argued that, for a certain soil fertility, there is an optimum plant density for which the crop maximally exploits the available nutrients.

The impact of plant density upon preferences in sowing strategies was analysed for a soil with a marginal water availability (A, Fig. 1). Monthly storage losses were set at $5 \%$. Results are presented in Figure 4. 

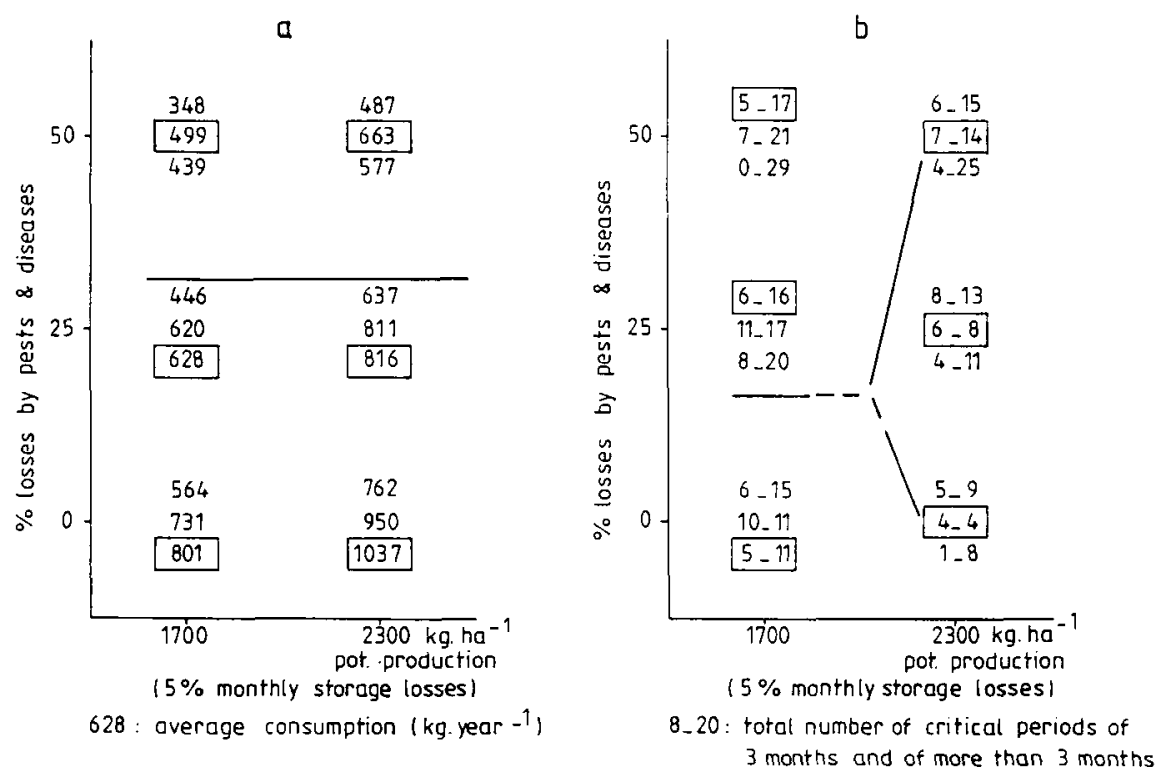

Fig. 5. Optimum strategies for maize as influenced by potential production. a: for maximizing average yearly consumption; b: for minimizing critical periods.

\section{Potential production}

The impact of potential production levels upon preferences for sowing strategies was examined by taking two different values for maximal potential production: 1700 and $2300 \mathrm{~kg} \mathrm{ha}^{-1}$ for a soil with marginal water availability (A, Fig. 1) and for monthly storage losses of $5 \%$. Results are presented in Figure 5.

\section{Conclusions and discussion}

\section{Water availability}

For all simulations (A, B and C; Fig. 1), when maximizing the average yearly consumption, Strategy 3 (sowing once a year in December) is preferred when yield reductions by pests and diseases and storage losses are small. Of course for simulation $C$ total yearly consumption will be higher as for simulation $A$, where water availability is marginal. When losses increase, Strategy 2 (sowing in September, December and March) becomes preferable. It is clearly shown that for maximizing yearly consumption the impact of losses upon preferences is by far dominant over water-availability. However, regarding the decision criterion of minimizing critical periods the preferred sowing strategy does greatly depend on water-availability. When the latter is marginal (A) only for low losses Strategy 3 is prefered and then an increase of losses leads to a preference for Strategy 1 (a scattered strategy, sowing 
each month). If water-availability increases ( $B$ and $C$ ) this scattered strategy becomes less attractive and also Strategy 3 will become less attractive for the farmer, even for low losses. Under a relatively high availability of soil water (C) for all combinations of losses Strategy 2 is preferable. Hence, when minimizing risks for food shortages (besides maize no alternative food available), water availability plays a dominant role in sowing strategies. When the water availability improves, soon Strategy 2 becomes preferable, independent of rates of losses.

\section{Plant density}

Given the questionable assumptions used in the simulation for different plant densities, results must be regarded with caution. For all strategies, production and consumption levels for high density were much lower than for low density (Fig. 5a). More research is needed to analyse the impact of plant density upon production. However, it can be concluded that the preference for a certain sowing strategy is dominated by losses by pests and diseases. Here again a concentrated strategy is preferred when these losses are low, whereas a scattered strategy gives the best results when these losses are high. When plant densities are further lowered, resulting in a higher production, it may be expected that Strategy 2 will become attractive. Obviously, for lower plant densities the errors made by the used model simplifications will increase.

\section{Potential production}

A somewhat higher potential production level roughly gives the same alterations in preferences than a better soil water availability, which were discussed earlier. For the analysed conditions of low soil water availability the results for a potential production level of $2300 \mathrm{~kg} \mathrm{ha}^{-1}$ (Fig. 5) approximate the results obtained with a level of $1700 \mathrm{~kg} \mathrm{ha}^{-1}$ with a somewhat better soil water availability (Fig. 2). Strategy 2 may become attractive when growing conditions are improved and when it is tried to minimize the risks for shortages. For maximizing average consumption, a higher potential production has no effect on the preferred sowing strategy.

\section{Decision criteria}

Of course, under all farming conditions attempts are needed to reduce losses and to improve water availability and soil fertility (i.c. potential production). If this is successful, production and consumption levels will increase. However, when we focus on optimal sowing strategies it can be concluded that in regions with little access to (markets for) alternative food, an improvement of water availability and soil fertility will result in other sowing strategies. This does not hold for regions where alternative food is available. Under these conditions, sowing strategies will alter only when losses by pests and diseases and/or storage are reduced.

One of the main problems in analysing sowing strategies is of an agro-economic nature. In this study this is made clear by presenting 2 criteria to decide upon for 
optimization, i.e. maximizing average yearly maize consumption and minimizing occurrence of periods with shortages. However, many other criteria can be used (a.o. Schweigman, 1985) and whether these correspond with the ones used by farmers in Mozambique will depend on environmental factors (region, soils) and socioeconomic factors (market, labour availability, alternative income, etc.).

\section{Acknowledgements}

The authors wish to thank E. Hendrix of the Dept of Mathematics of the Wageningen Agricultural University for his comments and suggestions. The first author worked at the Faculty of Agronomy, University Eduardo Mondlane in Maputo (Mozambique) from 1983 to 1985.

\section{References}

Belmans, C., J. G. Wesseling \& R. A. Feddes, 1983. Simulation model of the water balance of a cropped soil: SWATRE. Journal of Hydrology 63: 271-286.

Doorenbos, J. \& A. H. Kassam, 1979. Yield response to water. Irrigation and Drainage Paper 33. Food and Agricultural Organization, Rome, $193 \mathrm{pp}$.

Doorenbos, J. \& W. O. Pruitt, 1977. Crop water requirements. Irrigation and Drainage Paper 24. Food and Agricultural Organization, Rome, 144 pp.

Gardner, W. R., 1983. Soil properties and efficient water use: an overview. In H. M. Taylor, W. R. Jordan \& T. R. Sinclair (Eds), Limitations to efficient water use in crop production, pp. 45-64. American Society of Agronomy.

Goudriaan, J., 1982. Potential production processes. In: F. W. T. Penning de Vries \& H. H. van Laar (Eds), Simulation of plant growth and crop production, pp. 98-113. Pudoc, Wageningen.

Hall, D. W., 1970. Handling of storage of food grains in tropical and sub-tropical countries. Food and Agricultural Organization, Rome, $350 \mathrm{pp}$.

Keulen, H. van \& J. Wolf, 1986. Modelling of agricultural production: weather, soils and crops. Pudoc, Wageningen, $479 \mathrm{pp}$.

Nunes, E., D. Sousa \& I. Sataric, 1986. Research on the constraints to maize production in Mozambique. In: Proceedings of the First Eastern, Central and Southern Africa Regional Maize Workshop, Lusaka (Zambia), pp. 67-79. CIMMYT, Mexico.

Schouwenaars, J. M., 1988. Rainfall-irregularity and sowing strategies in southern Mozambique. Agricultural Water Management 13: 49-64.

Schouwenaars, J. M., G. H. Pelgum \& J. Swennenhuis, 1989. Research on plant-soil-water relations and its role in understanding sowing strategies. Water Resources Management 2: 255-267.

Schweigman, C., 1985. Operations research problems in agriculture in developing countries. University Press, Khartoum/Tanzania Publishing House, Dar es Salaam/University Press, Groningen, $361 \mathrm{pp}$. 